\title{
ETNODESENVOLVIMENTO, EDUCAÇÃO E DIVERSIDADE: EXPERIÊNCIAS ENTRE POVOS INDÍGENAS E AGRICULTORES FAMILIARES NO TERRITÓRIO SUDESTE PARAENSE
}

\author{
LUIZA DE NAZARÉ MASTOP-LIMA ${ }^{1}$ \\ UNIFESSPA-FAPESPA
}

\begin{abstract}
RESUMO: Analisam-se experiências de educação diferenciada entre povos indígenas e agricultores familiares no Território Sudeste Paraense em relação às demandas por educação mais voltada para suas realidades, que valorize os conhecimentos tradicionais e que sirva também de instrumento político para construção e manutenção da identidade desses sujeitos sociais. $O$ aumento da oferta de cursos técnicos e de ensino superior que atendam às demandas desses povos e comunidades tradicionais é um dos focos da análise, tido como resultado da atuação de movimentos indígenas e de movimentos sociais do campo na construção de etnodesenvolvimento naquela região. A observação direta e participante, as entrevistas com lideranças tradicionais e políticas tanto entre agricultores quanto entre os indígenas, assim como com dirigentes de órgãos e instituições envolvidos neste processo, foram meios para a coleta de dados necessários à análise. Vê-se que o protagonismo dos movimentos indígenas e do campo foi fundamental e indispensável ao processo.
\end{abstract}

PALAVRAS-CHAVE: diversidade; identidade; movimentos indígenas; movimentos sociais do campo; Estado.

ABSTRACT: Differentiated learning experiences among indigenous peoples and family farmers in the Southeastern Territory of Pará State were analyzed in relation to their demands for more suitable education policies - an education that takes under consideration their realities and values their traditional knowledge, being, at the same time, a political tool for the construction and maintenance of these social beings. The increasing availability of technical courses and university programs that meet the demand of these peoples and traditional communities is one of the focuses on this analysis, since it's a result of the actions of indigenous and rural social movements, adopting an ethnodevelopment perspective. Direct and participant observation, interviews with traditional and political leaderships of family farmers and indigenous people as well as with directors of organizations and institutions involved in this process, were means of collecting the necessary data to this analysis. The study concluded that the role played by indigenous and rural movements was essential to the process.

KEYWORDS: diversity; identity; indigenous movements; rural movements; State.

\footnotetext{
${ }^{1}$ Graduada em Ciências Sociais, mestre em Antropologia e doutora em Antropologia Social, pela Universidade Federal do Pará (UFPA). Docente no Instituto de Estudos em Desenvolvimento Agrário e Regional (IEDAR) da Universidade Federal do Sul e Sudeste do Pará (UNIFESSPA). Possui experiência de ensino, pesquisa e extensão em Etnologia Indígena e Antropologia Rural, sobretudo nos temas: conhecimentos tradicionais; identidade étnica; território; diversidade sociocultural e gênero. E-mail: luizamastop@ hotmail.com.
} 
Palavras iniciais...

As concepções de educação escolar diferenciada reivindicada junto ao Estado brasileiro por movimentos sociais indígenas e do campo no Território Sudeste Paraense são o foco de análise deste artigo, principalmente no que diz respeito aos processos de mobilização política desses movimentos sociais que, a partir dos princípios do etnodesenvolvimento, contribuem para a construção da diversidade sociocultural neste espaço social.

$\mathrm{O}$ artigo integra a tese intitulada Povos indígenas e agricultores familiares: a luta pela construção da identidade e da diversidade no Território Sudeste Paraense, elaborada por mim no âmbito do Programa de Pós-Graduação em Antropologia (PPGA), da Universidade Federal do Pará (UFPA), sendo a pesquisa financiada pela Fundação Amazônia Paraense (FAPESPA), por meio de uma bolsa de doutorado, entre os anos de 2010 e 2014.

Os dados aqui apresentados foram coletados a partir de trabalho de campo na cidade de Marabá, Estado do Pará, na aldeia Sororó, onde mora o povo indígena Aikewára, e no Projeto de Assentamento (PA) Belo Horizonte, com um grupo de agricultores familiares. $O$ trabalho de campo ocorreu nos meses de fevereiro, março, maio e junho de 2011 , período em que foram realizadas entrevistas semiestruturadas com dirigentes de movimentos sociais indígenas e do campo, principalmente com representantes da Federação dos Trabalhadores na Agricultura (FETAGRI) e o Movimento dos Trabalhadores Rurais Sem Terra (MST), que atuam no Território Sudeste Paraense.

Foi realizada, ainda, uma entrevista com a representante da $4^{a}$ Unidade Regional de Educação (4 ${ }^{\mathrm{a}}$ URE), órgão local vinculado à Secretaria de Educação do Estado do Pará (SEDUC), ao qual estão vinculadas algumas escolas indígenas e em assentamentos de reforma agrária onde atuam a FETAGRI e o MST. Além disso, apresentam-se dados coletados a partir de 
observação direta e participante na escola da aldeia Sororó e do PA Belo Horizonte.

A educação escolar compõe a pauta de reinvindicação de direitos tanto pelos povos indígenas quanto pelos movimentos sociais do campo, como veremos ao longo do texto, e é defendida pelos mesmos como uma necessidade básica para fortalecimento de suas identidades e modos de vida. Um dos problemas apontados por esses sujeitos sociais em relação à educação escolar nas aldeias e nos assentamentos é que ela precisa ser mais integrada às realidades socioculturais por eles vividas. Como o Estado é ineficiente quanto ao atendimento do direito à educação escolar diferenciada, esses sujeitos se mobilizam, criam estratégias e lutam para que o Estado reconheça suas escolas e contrate professores que possam trabalhar para efetivar a educação escolar segundo as visões desses sujeitos.

Dentre os diversos problemas enfrentados pelos movimentos sociais indígenas e do campo para a garantia do direito à educação escolar diferenciada, há uma questão que se destaca, que é em relação à construção do território por eles. Isso acontece porque a análise se dá em um território criado pelo Estado brasileiro, que não coincide com os territórios de atuação desses movimentos sociais. A concepção do Estado de território entra em contraste e disputa com as concepções locais de território.

Desta forma, ao terem de negociar questões relativas à educação escolar com o Estado, os povos indígenas, os agricultores familiares e suas representações precisam fazê-lo a partir do que o Estado apresenta como território, mas isso causa problemas internos aos movimentos, que precisam muitas vezes refazer trajetórias de atuação ou mesmo atuar em mais de um território, conforme a divisão feita pelo Estado. Vejamos como isso acontece na prática.

\section{O Território Sudeste Paraense: um espaço social de diversidade}


O Território Sudeste Paraense é um território criado pelo Estado brasileiro em 2008, no âmbito do programa Territórios da Cidadania². Ele é aqui tomado como o espaço social (BOURDIEU, 1989) 3 de observação e análise a partir do qual lanço um olhar sobre o campo ${ }^{4}$ da educação.

Como dito anteriormente, as concepções de território desses sujeitos sociais não necessariamente coincidem com a do Estado, mas precisam estar em constante interação com o que o Estado concebe enquanto território, pois é assim que se vão formando os campos de negociação e luta ${ }^{5}$ por direitos à diferença demandados por povos indígenas e agricultores familiares, como o é o campo da educação.

Neste sentido, gostaria, em primeiro lugar, de situar brevemente fatores sociais, políticos e econômicos que antecedem a construção deste espaço social hoje conhecido como Território Sudeste do Pará, a fim de mostrar como foi se construindo a diversidade sociocultural neste espaço. Em seguida, reflito sobre as diferentes concepções de território em jogo, para depois adentrar no campo da educação escolar e diferenciada, demandada por povos indígenas e agricultores familiares neste espaço social.

\footnotetext{
${ }^{2}$ Uma primeira versão deste programa foi criada em 2003 pela Secretaria de Desenvolvimento Territorial (SDT), do Ministério do Desenvolvimento Agrário (MDA), sob a denominação de Programa dos Territórios Rurais. O objetivo deste programa era promover o desenvolvimento rural sustentável no Brasil; o programa Territórios da Cidadania manteve o mesmo objetivo.

${ }^{3}$ A noção de espaço social formulada por Bourdieu refere-se a um espaço em que "os agentes e grupos de agentes são assim definidos pelas suas posições relativas neste espaço. Cada um deles está acantonado numa posição ou numa classe precisa de posições vizinhas, quer dizer, numa região determinada do espaço, e não se pode ocupar realmente duas regiões opostas do espaço - mesmo que tal seja concebível. Na medida em que as propriedades tidas em consideração para se construir este espaço são propriedades actuantes, ele pode ser descrito também como campo de forças, quer dizer, como um conjunto de relações de força objectivas impostas a todos os que entrem nesse campo e irredutíveis às intenções dos agentes individuais ou mesmo às interacções directas entre os agentes" (BOURDIEU, 1989, p. 134 - itálicos do autor).

${ }^{4}$ A noção de campo é assim explicada por Bourdieu: "Um campo, e também o campo científico, se, define entre outras coisas através da definição dos objetos de disputas e dos interesses específicos que são irredutíveis aos objetos de disputas e aos interesses próprios de outros campos (não se poderia motivar um filósofo com questões próprias dos geógrafos) e que não são percebidos por quem não foi formado para entrar neste campo (cada categoria de interesses implica na indiferença em relação a outros interesses, a outros investimentos, destinados assim a serem percebidos como absurdos, insensatos, ou nobres, desinteressados). Para que um campo funcione, é preciso que haja objetos de disputas e pessoas prontas para disputar o jogo, dotadas de habitus que impliquem no conhecimento e no reconhecimento das leis imanentes do jogo, dos objetos de disputas, etc" (BOURDIEU, 1983, p. 89).

${ }^{5}$ Luta é um termo nativo que refere um trabalho que não é concreto, no sentido de tomar nas mãos as ferramentas de trabalho e abrir uma roça, arar a terra, caçar, pescar ou cuidar do gado, ou fazer consertos em cercas, por exemplo, mas é o trabalho de argumentar e interferir para que o argumento seja ouvido, sobretudo pelo Estado, junto ao qual os povos indígenas e agricultores familiares reivindicam direitos diferenciados, que atendam às especificidades deles.
} 
A região ${ }^{6}$ onde foi criado o Território Sudeste Paraense é uma região conhecida na literatura especializada, entre outras coisas, pela diversidade sociocultural, política e econômica e pelos conflitos sociais e fundiários (LARAIA; DAMATTA, 1967; VELHO, 1972; DE REYNAL et al., 1996; EMMI, 1999; HÉBETTE, 2004; SIMÕES, 2006; ASSIS, 2007; NAVEGANTES-ALVES, 2011 ).

Autores como Laraia e DaMatta (1967), Velho (1972), De Reynal et al. (1996), Emmi (1999) e Hébette (2004) são referências fundamentais para se conhecer a história de ocupação da Região Sudeste do Pará, que ocorreu de forma voluntária e/ou planejada, seja a partir das políticas governamentais de colonização, seja a partir da mobilização política de movimentos sociais do campo (ASSIS, 2007).

Neste processo de ocupação, as migrações para a região ganharam destaque do ponto de vista social, econômico e político por possibilitarem, entre outros aspectos, a formação de uma densidade populacional no campo, que se organizou politicamente ao longo da história de luta pela terra, expressa pela atuação de sindicatos, associações, cooperativas, atrelados a movimentos sociais do campo, como a Federação dos Trabalhadores na Agricultura (FETAGRI) e o Movimento dos Trabalhadores Rurais Sem Terra (MST), entre outros (GUERRA, 2001; ASSIS, 2007).

Com o processo de ocupação e das relações sociais, políticas e econômicas estabelecidas a partir dele, houve o surgimento de elites locais de poder econômico e político que disputavam e/ou disputam a terra e os recursos naturais disponíveis, não apenas com trabalhadores rurais que para a região migraram, mas também com povos indígenas que habitam a região há séculos.

Dessa forma, paralelamente à organização dos agricultores também se testemunhou o aparecimento de famílias que dominavam a exploração e a comercialização de castanha-do-pará (Bertholletia excelsa); grandes fazendeiros especializados na atividade pecuária; madeireiros; empresários da mineração, entre outros, agentes sociais que, pelo poder econômico que tinham/têm, dominavam/dominam

\footnotetext{
${ }^{6}$ Mesmo estando ciente da crítica feita por Bourdieu (1989) à ideia de região, mantenho aqui o termo por assim estar referido na literatura especializada; a noção de espaço social é por mim utilizada na análise das relações estabelecidas entre os agentes sociais que interagem no campo da educação no Território Sudeste Paraense.
} 
também os grandes comércios nas cidades e a política regional (EMMI, 1999; HÉBETTE, 2004).

Ao longo da história de ocupação da região, diferentes visões de mundo e representações sobre o território coexistem e por vezes conflitam e entram em disputa. Atualmente, se tomarmos a classificação do Instituto Brasileiro de Geografia e Estatística (IBGE), por exemplo, a região é entendida como a Microrregião de Marabá, localizada a cerca de $550 \mathrm{~km}$ de distância da cidade de Belém, Estado do Pará, no sentido sudeste.

A classificação da Secretaria de Desenvolvimento Territorial (SDT), do Ministério do Desenvolvimento Agrário (MDA), indica que, em 2003, sete municípios da região formavam o chamado Território Rural Sudeste do Pará, base para o atual Território da Cidadania Sudeste Paraense, criado em 2008 pela mesma secretaria, constituído de 14 municípios?. Isso revela que no interior do próprio Estado há diferentes concepções de território.

Visto pelo ponto de vista de um povo indígena que habita a região, por exemplo, os Aikewára ${ }^{8}$, o território tem outra configuração, constituída por elementos êmicos. Da mesma forma, pelo ponto de vista de um grupo de agricultores familiares assentados ao Projeto de Assentamento Belo Horizonte, o território por eles construído se diferencia daquele marcado pelo IBGE ou pela SDT, como veremos melhor ao longo do texto. As diferentes concepções de território vão se tornando mais visíveis à medida que os diferentes agentes sociais ocupam posições relativas no espaço social (BOURDIEU, 1989).

Em um espaço social em que a diversidade de agentes sociais é uma característica marcante, como pudemos perceber pelo histórico de ocupação do lugar, focaremos nosso olhar nos povos indígenas e nos agricultores familiares, assim como nas relações por eles estabelecidas com o Estado no campo da educação escolar, por estarem estes agentes

\footnotetext{
${ }^{7}$ Brejo Grande do Araguaia; Canaã dos Carajás; Curionópolis; Itupiranga; Marabá; Nova Ipixuna; Palestina do Pará; Parauapebas; Piçarra; São Domingos do Araguaia; São Geraldo do Araguaia; São João do Araguaia; Bom Jesus do Tocantins; Eldorado dos Carajás (PORTAL DA CIDADANIA, 2014).

${ }^{8}$ Povo indígena classificado como Tupi, que habita a Área Indígena Sororó, localizada nos municípios de São Geraldo do Araguaia, São Domingos do Araguaia e Marabá, no sudeste do Pará. A autodenominação do povo significa "nós, a gente" (LARAIA, 1967; BELTRÃO, 1998; MASTOP-LIMA, 2002; MATTA DA SILVA, 2007).
} 
lutando por educação escolar diferenciada, que venha a fortalecer seus projetos de etnodesenvolvimento.

Observamos que, pela concepção de território do Estado a partir da SDT, no Território Sudeste Paraense há sete povos indígenas: Aikewára (municípios de São Domingos do Araguaia e São Geraldo do Araguaia); Xikrín do Cateté (municípios de Parauapebas e Canaã dos Carajás); Gavião Parkatêjê; Kyikatêjê; Akrãtitatêjê (município de Bom Jesus do Tocantins); Atikum (município de Itupiranga e Canaã dos Carajás) e Guajajara (município de Itupiranga). Desses povos, os Parkatêjê, os Akrãtikatêjê e os Kyikatêjê habitam na Reserva Indígena Mãe Maria; os Aikewára, na Área Indígena Sororó; os Xikrín, na Terra Indígena Cateté; e os Atikum e os Guajajara moram em lotes agrícolas do Instituto Nacional de Colonização e Reforma Agrária (INCRA).

A Superintendência Regional (SR 27) do INCRA em Marabá possui o registro de criação de 495 assentamentos até 2011 , dos quais 219 estão localizados nos 14 municípios que compõem o atual Território Sudeste Paraense, sendo que este número aumenta a cada ano.

A maior parte deste espaço social, cerca de $80 \%$ da área total, é formada por assentamentos de reforma agrária, terras indígenas e áreas de conservação, demonstrando que a agricultura praticada na região caracteriza-se mais por ser familiar, não patronal, segundo dados do Plano Territorial de Desenvolvimento Rural Sustentável (PTDRS/2010).

No campo econômico, a produção agrícola dos assentamentos no Território é comercializada também a partir da Cooperativa Camponesa do Araguaia-Tocantins (COOCAT), a primeira criada com este objetivo, que em 2003 passou a ser a Federação das Cooperativas da Agricultura Familiar do Sul do Pará (FECAT), à qual estão vinculadas pelo menos sete cooperativas.

Além da produção dos assentamentos, pela FECAT também já se comercializou produtos como o açaí e o cupuaçu coletado em áreas indígenas. As cooperativas no Território Sudeste Paraense funcionam como uma das estratégias adotadas pelos agricultores familiares que ali habitam para tomar parte no mercado local, regional, nacional e internacional; uma alternativa à imposição de grandes produtores agrícolas no país que investem no monocultivo de produtos transgênicos, como a soja e o milho, por exemplo. 
O setor agropecuário no Território também se destaca pela pecuária, sendo que os maiores rebanhos bovinos encontram-se em Marabá, Itupiranga e São Geraldo do Araguaia, contabilizando mais de 300.000 cabeças de gado, de acordo com dados do PTDRS. Em relação à tendência da pecuária para o gado de corte, observou-se, ao longo dos anos, dificuldades enfrentadas pelas famílias e transformações nas paisagens dos assentamentos rurais, como estradas com baixas condições de trafegabilidade e falta de escoamento da produção agrícola, por exemplo, em que as áreas de roças deram lugar a pastos (HÉBETTE, 2004; OLIVEIRA et al., 2003; LABORATÓRIO SÓCIO-AGRONÔMICO DO TOCANTINS; SECRETARIA DE DESENVOLVIMENTO TERRITORIAL, 2006 e 2010; NAVEGANTES-ALVES, 2011 ; MASTOP-LIMA e BELTRÃO, 2015).

O maior investimento na rede viária dos municípios do Território, observada a partir dos anos 1995, assim como o aumento da atividade pecuarista na região influenciou a decisão dos agricultores assentados de investir também na produção leiteira, vendendo leite para laticínios formais e informais localizados, sobretudo, em São João do Araguaia e São Domingos do Araguaia, ainda segundo informações encontradas no PTDRS.

Esta decisão, no entanto, levou à acusação, anos mais tarde, pela mídia, de que os agricultores familiares eram os maiores responsáveis pelo desmatamento na Amazônia, o que gerou muitos protestos pelos movimentos sociais do campo em todo o Brasil, contra a criminalização da ação dos movimentos e dos agricultores. Acusação esta que também foi refutada por estudiosos do assunto, que apontaram como causas principais do desmatamento na Amazônia a atuação de médios e grandes pecuaristas e a abertura de estradas (FEARNSIDE, 2006), cujo principal responsável é o Estado e não os agricultores familiares.

A atividade madeireira e a produção de carvão vegetal também provocaram mudanças na paisagem dos municípios, e acarretam danos ambientais e prejuízos à saúde dos habitantes das zonas rural e urbana, sendo grande o índice de doenças relacionadas à alergia provocada pela fumaça das queimadas nos assentamentos.

Há assentamentos, inclusive, a $20 \mathrm{~km}$ de Marabá, em que à beira da pista é vista cobertura vegetal secundária, mas que ao se entrar na área veem-se inúmeros fornos para produção de carvão vegetal para ser 
usado nas siderúrgicas da região; a mata secundária funciona como uma espécie de "capa" para encobrir a atividade predatória.

Quanto ao campo político, no Território enquanto espaço social nota-se a atuação de movimentos sociais do campo, tais como a FETAGRI e o MST. Além disso, os povos indígenas organizam-se em associações, tais como a Associação dos Povos Indígenas do Tocantins (APITO), e as associações indígenas que cada povo criou. A partir dos sindicatos, movimentos sociais e associações é que se mobilizam os sujeitos para a luta por direitos como educação, saúde, acesso e permanência à/na terra, assim como para a construção do território que cada povo ou comunidade tradicional possui.

Como dito anteriormente, algo que precisa ser observado em relação à atuação desses movimentos, ou mesmo das associações, é que o território da agricultura familiar por eles representados não tem a mesma ordenação que o Estado dá, pois a área de abrangência das ações por parte dos movimentos e associações não coincidem necessariamente com os municípios que compõem o Território Sudeste Paraense apenas.

A FETAGRI, por exemplo, trabalha com projetos de assentamento registrados entre os 495 sob a jurisdição da SR 27 do INCRA, com sede em Marabá, e com projetos de assentamentos localizados em outros 23 municípios que não compõem o território delimitado pela SDT. O mesmo acontece com o MST, que organiza cerca de 30 áreas de assentamento e 12 acampamentos, nem todos em municípios do Território Sudeste Paraense.

A APITO, além dos sete povos no Território, atende também aos povos Amanayé, Anambé e Guarani, localizados em municípios que não formam este território. Como podemos entender essas diferentes concepções de território e em que medida elas são contempladas ou não pela concepção estatal? Vejamos a seguir.

\section{Terra e território: disputas e interesses em jogo num espaço social}

Se tomarmos a terra como referencial para análise, vemos que ela é um elemento presente tanto na luta de povos indígenas quanto na de 
agricultores no Território Sudeste Paraense, e que do ponto de vista do aspecto conceitual há diferença entre terra e território.

A discussão feita por Seeger e Viveiros de Castro (1979), assim como Luciano (2006 e 2008), sobre a questão da diferença entre terra e território, ao mesmo tempo em que mostra a relação entre eles, serve de base tanto para refletir sobre a questão em relação aos agricultores quanto em relação aos povos indígenas.

Para esses autores, terra diz respeito ao espaço físico, geográfico em que vive um povo indígena, e território representa a relação que este povo estabelece com esse espaço físico, em que, nas palavras de Luciano: "[p]ara os povos indígenas, o território compreende a própria natureza dos seres naturais e sobrenaturais, onde o rio não é simplesmente o rio, mas inclui todos os seres, espíritos e deuses que nele habitam" (LUCIANO, 2006, p. 101).

Com isso, não estou afirmando aqui que terra e território têm o mesmo significado tanto para povos indígenas quanto para agricultores, mas sim que tanto em relação aos povos indígenas quanto em relação aos agricultores há uma dimensão material, física, e outra imaterial, que dá sentidos diferenciados à relação destes povos e comunidades tradicionais com os ambientes em que vivem.

A terra é um elemento importante para a construção do território e da identidade de um povo, mas não é determinante deles, pois, segundo Oliveira Filho (1999), no processo de construção de um território e de estabelecimento de uma identidade étnica deve-se atentar para o processo de territorialização desse povo, que consiste em um

... processo de reorganização social que implica: i) a criação de uma nova unidade sociocultural mediante o estabelecimento de uma identidade étnica diferenciadora; ii) a constituição de mecanismos políticos especializados; iii) a redefinição do controle social sobre os recursos ambientais; iv) a reelaboração da cultura e da relação com o passado (OLIVEIRA FILHO, 1999, p. 20 - grifos do autor).

Almeida (2008), ao refletir sobre as terras tradicionalmente ocupadas no Brasil, assim define o processo de territorialização: 
O processo de territorialização é resultante de uma conjunção de fatores, que envolvem a capacidade mobilizatória, em torno de uma política de identidade, e um certo jogo de forças em que os agentes sociais, através de suas expressões organizadas, travam lutas e reivindicam direitos face o Estado. As relações comunitárias neste processo também se encontram em transformação, descrevendo a passagem de uma unidade afetiva para uma unidade política de mobilização ou de uma existência atomizada para uma existência coletiva. A chamada 'comunidade tradicional' se constitui nesta passagem. O significado de 'tradicional' mostra-se, deste modo, dinâmico e como um fato do presente, rompendo com a visão essencialista e de fixidez de um território, explicado principalmente por fatores históricos ou pelo quadro natural, como se a cada bioma correspondesse necessariamente uma certa identidade. A construção política de uma identidade coletiva, coadunada com a percepção dos agentes sociais de que é possível assegurar de maneira estável o acesso a recursos básicos, resulta, deste modo, numa territorialidade específica que é produto de reivindicações e lutas (ALMEIDA, 2008, p. 118-119).

Pelo que escreve Almeida, podemos ver no processo de territorialização dos movimentos sociais do campo e indígenas no Território Sudeste Paraense que há diferentes territórios em disputa e em negociação. Os movimentos sociais, por suas lutas, não podem deixar de considerar o que o Estado concebe enquanto território, ainda que esta concepção tenha sido feita com a participação deles; e tampouco podem abandonar suas concepções nativas de território, criadas e recriadas a partir da mobilização política dos agentes sociais que fazem estes movimentos. As negociações e disputas não são apenas com o Estado, mas também entre estes diferentes movimentos, uma vez que os territórios se sobrepõem.

Ainda que as terras indígenas estejam demarcadas, por exemplo, os territórios construídos pelos diversos povos indígenas no Território Sudeste Paraense sofreram perdas históricas de terras, mas ainda são vivenciados a partir das narrativas orais, da mitologia e das narrativas históricas.

Além disso, há casos, como o dos Gavião, por exemplo, que foram remanejados para o município de Bom Jesus do Tocantins, para a Reserva 
Indígena Mãe Maria, que tiveram que reconstruir o território com os recursos que thes foram disponibilizados e atualmente vê-se, entre as três etnias que compõem este grupo, um movimento para vivenciar suas territorialidades específicas, ainda que numa mesma terra, lutando por educação, saúde, projetos produtivos que visem ao etnodesenvolvimento dos povos.

Acrescenta-se a este movimento de construção de territórios a disputa pelo reconhecimento de suas identidades diferenciadas pela empresa privada VALE, que deverá repassar recursos de forma igualmente diferenciada aos três povos por conta da exploração e transporte de minérios que faz na região, causando prejuízos a estes e a outros povos, sobretudo pela estrada de ferro que corta a Reserva Indígena Mãe Maria.

A concepção material e imaterial do território é ratificada por Saquet (2007, p. 24), segundo o qual, “... o território significa natureza e sociedade; economia, política e cultura; ideia e matéria; identidades e representações; apropriação, dominação e controle... terra, formas espaciais e relações de poder; diversidade e unidade.", reforçando a concepção dos demais autores de que a terra é um dos componentes do território e não pode ser com ele confundida.

Entre os Aikewára, por exemplo, os mais velhos e experientes do povo citam em suas narrativas míticas e históricas as mudanças sofridas no território tradicional por ocasião do contato com a sociedade não indígena. Segundo eles, o território aikewára compreendia uma área que se estendia da Serra das Andorinhas (distante cerca de 200 km de Marabá) até Marabá. Com a demarcação de suas terras, a Serra das Andorinhas ficou de fora da Área Indígena Sororó e o povo Aikewára luta pela retomada destas terras para o seu território.

Os Aikewára lançam mão, entre outros, do argumento de que ali na Serra das Andorinhas estão enterrados muitos dos seus. O argumento é acompanhado pela ameaça, inclusive, de fazerem escavações por conta própria nos cemitérios ali localizados para provar aos não indígenas que a reivindicação deles é legítima.

A Serra das Andorinhas é referida no mito de origem do povo Aikewára como o cenário onde se deu o surgimento deles. Em 1996, a 
Serra das Andorinhas passou a ser parque estadual9, com entrada supostamente controlada, mas de livre acesso aos Aikewára, e passou a compor a representação que o Estado faz do que seja o território para ele.

Entre os agricultores, a luta pela terra, a permanência nela a partir da garantia de direitos como educação, saúde e segurança alimentar, varia entre os movimentos sociais do campo. A FETAGRI tem uma metodologia de organização, mobilização e gestão dos assentamentos a ela ligados, e o MST tem outra.

Há territórios rurais que não necessariamente se constituíram a partir da ação direta de movimentos sociais do campo, como é o caso, por exemplo, do território analisado por Emília Pietrafesa de Godoi (1998) em povoados do sertão do Piauí, em que a memória relativa a um ancestral comum é o elemento principal de constituição daquele território.

Os agricultores no Território Sudeste Paraense, ainda que mobilizados em identidades coletivas genéricas, como o são os representados pela FETAGRI e pelo MST, apresentam diferenças entre si em relação aos processos de territorialização e às territorialidades.

Nestes processos, os lugares dos quais migraram também constituem os territórios. Os projetos de assentamento, ainda que correspondam a áreas de terra delimitadas, não representam um fim em si, mas um meio para que estas territorialidades sejam vivenciadas; eles são, por excelência, territórios plurais.

No caso do PA Belo Horizonte, por exemplo, vê-se entre os agricultores, a partir da mobilização política pela associação, a preocupação em fazer daquelas terras meio para expressar o PA enquanto território de agricultores familiares; há uma identidade coletiva e diferenciada pela qual eles se mobilizam e lutam, mesmo considerando as diferenças entre eles.

Pelo exposto, mostra-se que a terra é fundamental para a viabilização dos projetos políticos e de sociedade tanto de povos indígenas quanto de agricultores familiares neste espaço social, que

\footnotetext{
${ }^{9}$ Parque Estadual Serra das Andorinhas ou Serra dos Martírios, como ficou conhecida a área pelo fato de que muitos corpos foram lá enterrados na época da Guerrilha do Araguaia. O Parque foi criado pela Lei 5.982, de 25 de julho de 1996 (SEMAS, 2014).
} 
encontram-se em constante negociação e disputa entre si e entre os interesses do estado brasileiro, mas qual a relação disso com a educação escolar?

Povos indígenas e agricultores familiares precisam, neste caso, do meio físico terra, pois é a partir dele que se concretiza a construção de escolas que poderão ser usadas como instrumentos políticos para construção de seus territórios, manutenção e valorização de suas identidades, garantia do direito à diferença, o que parece óbvio, mas que não deve ser desprezado, uma vez que a terra é o foco de inúmeros conflitos sociais e políticos no meio rural brasileiro. Terra, território e educação escolar estão intimamente relacionados: ter terra é uma forma de viabilizar um projeto de escola diferenciada e construir território de pertença social diferenciada; ter educação escolar diferenciada é uma maneira de permanecer na terra e manter o território e a identidade, como veremos no próximo tópico.

\section{Educação escolar diferenciada: caminhos para etnodesenvolvimento e manutenção de identidades}

Apesar de grupos sociais como os povos indígenas e os agricultores familiares serem diferentes entre si e mesmo em relação a seus pares, eles enfrentam problemas semelhantes do ponto de vista da educação escolar e, em alguns casos, também encontram soluções semelhantes para os problemas. Do meu ponto de vista, essas aproximações não se dão ao acaso, mas refletem o olhar e o tratamento que o Estado confere à diferença.

A partir de entrevistas realizadas com lideranças políticas representantes de povos indígenas e agricultores familiares no Território Sudeste Paraense, assim como com representantes de instituições estatais responsáveis pela educação escolar, verifiquei que os problemas enfrentados pelos citados agentes sociais são: i) não oferta de todos os níveis de ensino em escolas indígenas ou nos assentamentos rurais, quando existem; ii) falta de professores; iii) falta de formação cultural e política aos professores "de fora" desses grupos socialmente diferenciados que atuam em escolas indígenas ou em assentamentos; iv) 
falta de transporte escolar, ou em condições inadequadas de uso, quando existe; v) condições estruturais inadequadas das escolas, quando existem; vi) currículo unificado.

Assim como identifiquei proximidades em relação aos problemas, notei algumas estratégias comuns adotadas pelos diferentes agentes sociais para sanar as questões acima citadas: i) estabelecimento de parcerias com instituições públicas para a oferta dos níveis faltantes de ensino; ii) formação/capacitação cultural e política de professores no interior dos movimentos sociais para posterior luta por contratação dos mesmos pela Secretaria Estadual de Educação (SEDUC) ou pelas Secretarias Municipais de Educação (SEMED); iii) improvisação de transporte escolar; iv) funcionamento de escolas em instalações provisórias; v) adequação do currículo às realidades locais e concomitante luta com a SEDUC para que as atividades culturais de cada grupo seja contabilizada como dia letivo. Embora semelhantes e próximos esses problemas e estratégias de solução deles são vivenciados de forma diferenciada de acordo com os agentes sociais envolvidos. Vejamos alguns exemplos.

A situação da educação escolar indígena no Território Sudeste Paraense é analisada, entre outros, por Rosani de Fatima Fernandes (2010), indígena kaingang, pedagoga e mestre em Direito pela UFPA. Além de analisar a educação escolar indígena de maneira geral, a autora trabalha com um caso específico de escola conforme almejam os povos indígenas: a Escola Indígena Tatakti Kyikatêjê. Esta escola está localizada na aldeia dos Kyikatêjê e oferece ensinos fundamental e médio aos indígenas não apenas que habitam na aldeia, mas a outros de diferentes etnias que para lá migram para estudar.

A partir da escola foram elaborados e desenvolvidos com professores indígenas e não indígenas, em conjunto com os estudantes e demais membros do povo Kyikatêjê, projetos pedagógicos que tinham por objetivo principal promover a integração entre o que se ensina na escola e o que se vivencia no quotidiano sociocultural do povo.

Foram desenvolvidos projetos sobre pintura corporal, alimentos tradicionais, o sistema de nominação do povo Kyikatêjê, os artefatos por eles produzidos, entre outros. Para a execução dos projetos também se contou com a parceria estabelecida com a Universidade Federal do Pará 
(UFPA), a partir do Programa de Políticas Afirmativas para Povos Indígenas e Populações Tradicionais (PAPIT), e desta parceria resultaram algumas publicações e material de apoio didático ${ }^{10}$.

O trabalho desenvolvido na Escola Indígena Tatakti Kyikatêjê tem servido de exemplo para os demais povos indígenas da região, que procuram parceria com instituições de ensino superior para a promoção da educação escolar diferenciada pela qual lutam, pois, segundo declarou a representante da $4^{\mathrm{a}}$ Unidade Regional de Educação ( $4^{\mathrm{a}} \mathrm{URE}$ ), vinculada à SEDUC, esta escola indígena em todo o Território Sudeste Paraense é a única que oferta três níveis de ensino: fundamental I e II e o médio.

Mas isso só foi possível pelo fato de que os próprios Kyikatêjê, por meio de sua associação, ofereceram aos professores não indígenas que atuavam na aldeia formação sobre a cultura do povo e posterior valorização dela no ambiente escolar, resolvendo desta forma dois problemas: o da inadequação do currículo e o da falta de formação para os professores.

Com os professores devidamente capacitados, os Kyikatêjê foram para o embate político e administrativo com a SEDUC para a contratação dos professores por eles treinados, processo este nem sempre fácil, pois, de acordo com Fernandes (2010), muitos dirigentes de escolas indígenas esbarram em dificuldades burocráticas.

Entre os Aikewára, por exemplo, a parceria estabelecida com a UFPA a partir do Campus de Marabá e do PAPIT tem gerado a produção de material de apoio didático para ser utilizado na escola da aldeia, que versa sobre a mitologia do povo, sobre a avifauna, sobre os instrumentos musicais, entre outros (BELTRÃO e MASTOP-LIMA, 2009 e 2010; SILVA; BELTRÃO e MASTOP-LIMA, 2011 ).

Além da UFPA, ainda em relação aos níveis fundamental e médio, outro importante parceiro dos povos indígenas no Território Sudeste Paraense é o Instituto Federal de Educação, Ciência e Tecnologia do Pará (IFPA), que oferece para eles curso técnico em Agroecologia, criado em 2009. A Universidade Estadual do Pará (UEPA) também integra o grupo dos parceiros, a partir da oferta do curso de Licenciatura Intercultural

\footnotetext{
${ }^{10}$ A maior parte do material produzido no âmbito das oficinas pedagógicas ainda é de acesso restrito, mas algumas publicações foram feitas e distribuídas em escolas municipais e estaduais, indígenas e não indígenas, no Território. Entre as publicações pode-se citar: Beltrão e Mastop-Lima (2009); Beltrão e Fernandes (2010) e Fernandes (2010).
} 
Indígena, criado em 2012, do qual fazem parte como estudantes 14 Aikewára, entre os 91 indígenas selecionados para as 100 vagas ofertadas. No âmbito do ensino superior, ainda, os movimentos sociais indígenas contam com a reserva de duas vagas em cada curso de graduação da UFPA, em que os candidatos são submetidos a Processo Seletivo Especial (PSE).

Os povos indígenas no Território Sudeste Paraense enfrentam problemas em relação a transporte escolar porque precisam sair das aldeias para dar continuidade aos estudos, uma vez que na maioria das escolas nas aldeias não é ofertado o ensino médio, é claro. Nestes casos, uma das estratégias adotadas pelos movimentos indígenas é solicitar à FUNAI o transporte, mas muito raramente a demanda é atendida, ou então os estudantes são transportados nos próprios carros ou caminhões das associações indígenas. Raros são os casos em que os povos indígenas possuem micro-ônibus usado para o transporte escolar. Além disso, o deslocamento dos estudantes para as escolas não indígenas representa despesas extras para as associações indígenas, sobretudo com combustível.

Este problema, no entanto, aumenta quando se trata de ensino superior ofertado fora das aldeias, pois se torna praticamente inviável, do ponto de vista econômico, ir e vir das aldeias para a cidade de Marabá estudar, que é onde estão concentradas as universidades. A saída encontrada, muitas vezes, dependendo do número de estudantes por aldeia, é alugar uma casa na cidade que sirva de alojamento para os estudantes indígenas, mas esta é uma estratégia, em geral, adotada por povos indígenas que apresentam maiores condições financeiras.

Em casos em que apenas um ou dois indígenas de determinado povo é selecionado no PSE, eles costumam ficar na casa de algum conhecido na cidade ou mesmo partem para o aluguel de quitinetes. As despesas com os alugueis, no entanto, são apenas um item da longa lista de despesas que possuem os estudantes indígenas para se manter na universidade, pois há despesas com alimentação, fotocópias de textos, aquisição de livros e transporte, entre outras. Mesmo com a inclusão dos estudantes indígenas no Programa Bolsa Permanênciall na UFPA, o

\footnotetext{
${ }^{11}$ Programa criado pelo governo federal para a concessão de auxílio financeiro a estudantes em situação de vulnerabilidade socioeconômica, a estudantes indígenas e quilombolas, matriculados em universidades
} 
recurso recebido não é suficiente para cobrir todas as despesas, o que acaba gerando um alto número de desistência dos cursos pelos indígenas.

Mas este não é o único fator de desistência dos cursos, uma vez que a maioria dos estudantes indígenas na UFPA apresenta dificuldade em relação à aprendizagem, pois se deparam com uma metodologia de ensino não voltada para a diferença. $O$ que revela que ainda há muito o que se fazer do ponto de vista institucional para garantir a permanência desses estudantes na universidade, conforme indica Beltrão (2007).

Em relação aos agricultores familiares, os dados fornecidos em entrevistas com dois dirigentes de movimentos sociais do campo no Território Sudeste Paraense, a FETAGRI e o MST, mostram que os agricultores vinculados a eles enfrentam problemas semelhantes, mas as estratégias adotadas pelos movimentos variam conforme seus projetos de sociedade e território, assim como varia de acordo como concebem a pertença a um grupo socialmente diferenciado.

Com relação à oferta dos níveis de ensino, o problema se complica, pois, além disso, faltam escolas nos assentamentos, sobretudo os vinculados à FETAGRI. Para o MST o problema não se apresenta da mesma forma, embora também exista, pois um ambiente escolar necessariamente existe desde a instalação dos acampamentos ${ }^{12}$.

A falta de escolas nos assentamentos vinculados à FETAGRI continua sendo um dos principais problemas enfrentados por este movimento social do campo, segundo o então dirigente da FETAGRI entrevistado, o Sr. Francisco de Assis Solidade (mais conhecido como De Assis).

O ensino médio, por exemplo, é apontado por ele, como o principal "gargalo" da educação escolar pelo fato de que a não oferta dele quebra a continuidade da formação dos membros do movimento ou de seus filhos, futuros membros. Segundo De Assis, a formação profissional dos agricultores é um dos objetivos da FETAGRI. Pode-se perceber nas

\footnotetext{
públicas brasileiras. Mais informações sobre o Programa de Bolsa Permanência encontram-se na página virtual do Ministério da Educação (MEC) (PBP, 2014).

${ }^{12}$ Alguns dos problemas aqui citados enfrentados pelos movimentos sociais do campo estão também registrados na Declaração Final por uma Política Pública de Educação do Campo, formulada durante a II Conferência Nacional por uma Educação do Campo, realizada em Luiziânia, Goiás, no período de 02 a 06 de agosto de 2004.
} 
entrelinhas do que declara De Assis que esta quebra de continuidade de formação também interfere no processo de construção do território por eles concebido, assim como no fortalecimento da pertença socialmente diferenciada. Estes problemas geram outros, como a venda ou abandono dos lotes pelos assentados, que migram para as cidades em busca de educação escolar para seus filhos.

A educação escolar defendida pelos movimentos sociais do campo é a educação do campo, que se contrapõe à educação rural proposta pelo Estado brasileiro até os idos dos anos 90 do século passado. Trata-se da luta por uma educação escolar específica para os agricultores familiares, ou, nas palavras dos protagonistas dos movimentos sociais do campo, trata-se da luta

por um projeto de sociedade que seja justo, democrático e igualitário; que contemple um projeto de desenvolvimento sustentável do campo, que se contraponha ao latifúndio e ao agronegócio e que garanta:

- a realização de uma ampla e massiva reforma agrária;

- demarcação das terras indígenas;

- o fortalecimento e expansão da agricultura familiar/camponesa;

- as relações/condições de trabalho, que respeitem os direitos trabalhistas e previdenciários $x$ dos trabalhadoras e trabalhadores rurais;

- a erradicação do trabalho escravo e da exploração do trabalho infantil;

- o estímulo à construção de novas relações sociais e humanas, e combata todas as formas de discriminação e desigualdade fundadas no gênero, geração, raça e etnia;

- a articulação campo - cidade, o local - global.

(...) por um projeto de desenvolvimento do campo onde a educação desempenhe um papel estratégico no processo de sua construção e implementação (CONFERÊNCIA NACIONAL POR UMA EDUCAÇÃO DO CAMPO, 2, 2004).

Como se mostrou anteriormente, a atuação dos movimentos sociais do campo está para além dos municípios que formam o Território Sudeste Paraense. Para citar um exemplo dos problemas enfrentados com o ensino médio, o Sr. De Assis referiu o caso do município de Conceição do Araguaia (que não faz parte do Território Sudeste Paraense), em que há 
apenas duas escolas estaduais para atender toda a zona rural. Sobre este aspecto, ele fez uma crítica ao Estado no sentido de que as distâncias geográficas entre os assentamentos e dentro deles não são consideradas pelo Estado no momento da criação de escolas no campo, muito menos as dificuldades financeiras que as famílias enfrentam para chegar às escolas, quando chegam.

Em vista deste e de outros problemas referentes à oferta dos níveis de ensino, a estratégia adotada pela FETAGRI é o estabelecimento de parcerias com instituições como o INCRA e a UFPA, para a elaboração de projetos de cursos de ensinos fundamental, médio e superior voltados para os agricultores e filhos de agricultores vinculados ao movimento.

Neste sentido, uma das importantes conquistas da FETAGRI foi a criação, em 1996, da Escola Família Agrícola (EFA), que, tendo como base a metodologia da alternância, ofertou aos agricultores e seus filhos os níveis fundamental e médio de ensino (DIAS, 2007). A EFA funcionou até 2009, com recursos do Programa Nacional de Educação na Reforma Agrária (PRONERA).

Ainda segundo De Assis, há um investimento prévio do movimento e no interior dele na formação de candidatos ao ensino médio e superior, para o comprometimento político e social dos candidatos com o movimento. Esta é a construção do sentimento de pertença a um grupo, em primeiro lugar, para que ao longo da formação a pertença seja impressa em diferentes áreas do conhecimento científico. Nas palavras dele, em entrevista realizada em fevereiro de 2011 ,

Para participar dos cursos de nível superior, além do prérequisito básico, ter nível médio, o movimento estabelece alguns critérios: ter aptidão para o curso ofertado; comprometimento com a causa dos trabalhadores da agricultura, o que é uma precaução de não estar formando pessoas que venham utilizar seu conhecimento para crescimento apenas individual, como a empregabilidade nas prefeituras, criando problemas no quadro do movimento e na expectativa depositada nele pela organização (DE ASSIS, entrevista em 2011).

A falta de professores nas escolas dos assentamentos, também apontado por De Assis como um problema no campo da educação escolar no Território, é consequência, segundo ele, da baixa gratificação 
oferecida aos professores que vêm para a zona rural e resulta da falta de professores em proporção ao número de alunos, além da falta de qualificação dos primeiros.

Muitos professores, inclusive, acabam abandonando o trabalho em virtude das condições de realização dele ou da não adaptabilidade ao lugar. A estratégia adotada pela FETAGRI para superar este problema é investir na formação do seu próprio pessoal, que trabalha como voluntário nas escolas de nível fundamental nos assentamentos, mas muito ainda falta para o problema ser resolvido.

Enquanto que, para a FETAGRI, a falta de escolas nos assentamentos é um problema, o mesmo não se observou em relação ao MST, como dito anteriormente. Em entrevista com a Sra. Maria Raimunda César de Oliveira, a mesma afirmou que das 23 áreas de assentamento vinculadas ao MST e 10 acampamentos organizados pelo movimento até 2011 , somente uma área não tinha escola, porque o número de crianças para estudar ainda era muito pequeno.

A educação nos assentamentos do MST, de acordo com a Sra. Maria Raimunda, deu-se pela necessidade; segundo ela, "... o homem indo pra frente; com o tempo, acabou construindo que a luta tem que ser feita pela família e aí surgiu a educação...". A metodologia utilizada pelo movimento para a construção de uma educação escolar diferenciada começa com o projeto de "Ciranda da Leitura" incentivando as crianças à leitura, com resultados muito bons, de acordo com a fala de Maria Raimunda: "... muitas estão lendo sete livros por mês, o que é um número bom tendo em vista o país que estamos...". O aumento no número de livros lidos, segundo ela, deve-se a um trabalho de resenha oral feita pelos professores em sala de aula, o que incentiva bastante os alunos a lerem o livro resenhado.

A representante do MST em Marabá ressaltou em sua entrevista a relação entre terra e educação escolar. Para ela, a luta pela terra vai muito além da terra em si, já que depois dela conquistada várias pessoas lá estarão vivendo; e elas não precisam apenas de um lugar para morar e plantar. A sua "alma humana", segundo a Sra. Maria Raimunda, também precisa ser alimentada, principalmente por meio da educação escolar. A terra é apenas a primeira etapa de todas as conquistas. 
Ela, assim como o Sr. De Assis, concorda que ter terra sem educação escolar diferenciada estimula a saída dos assentados dos lotes; a educação escolar nos assentamentos é um incentivo à permanência na terra e à reprodução social dos agricultores familiares. A fala da Sra. Maria Raimunda, deixa claro que a educação escolar no MST é um meio para construção de uma sociedade mais igualitária, que contempla a diversidade de identidades sociais existentes, desde que esta educação escolar seja feita de forma diferenciada, integrando escola e cultura.

Se para o MST a falta de professores nas escolas dos assentamentos e dos acampamentos não é um problema, segundo a Sra. Maria Raimunda, o maior problema do movimento no Território "... é com a formação do professor. É difícil para ele criar vínculo com o grupo, a vida das pessoas e da comunidade...". Apesar de terem número quase proporcional de escolas por assentamento, é preciso mencionar que nem todas são reconhecidas pelo Estado e/ou município. As de assentamento são todas reconhecidas, enquanto entre as de acampamento há apenas uma escola reconhecida.

Ser militante no movimento não é um pré-requisito para ser professor das escolas no campo, mas no caso do MST, a grande maioria dos educadores é do movimento, o que corrobora com os argumentos lançados pelo Sr. De Assis, no que diz respeito a serem pessoas que estão mais próximas e envolvidas com a realidade onde atuam e são preparadas para a função que ocupam.

Para citar um exemplo de que faz diferença o projeto de educação das escolas estarem ligados ao projeto político e social do movimento, a entrevistada citou o êxito da Escola Crescendo na Prática, localizada no PA Palmares II, município de Parauapebas-Pará, que é a maior escola em área rural no Brasil, com 1.600 alunos, sendo a maioria dos professores que nela atuam é de militantes do MST.

Isso confirma o que aparece na Declaração por uma Política Pública de Educação do Campo, em que os movimentos sociais do campo afirmam defender "... uma educação que ajude a fortalecer um projeto popular de agricultura que valorize e transforme a agricultura familiar/camponesa e que se integre na construção social de um outro projeto de desenvolvimento sustentável de campo". 
Em relação aos professores que atuam nas escolas dos assentamentos e acampamentos, a Sra. Maria Raimunda diz que o movimento pressiona as secretarias municipais e estaduais de educação para a contratação de professores militantes do movimento, a fim de que possam influenciar a organização da escola junto aos demais professores que não são do movimento, e desta forma dar um tom diferenciado à educação formal realizada.

Este enfrentamento também ocorre em relação ao reconhecimento das escolas, pois, segundo ela, eles primeiro estruturam as escolas e a partir do funcionamento dela é que buscam o reconhecimento legal delas junto às secretarias de educação, estratégia esta também adotada pelos movimentos indígenas, como vimos anteriormente.

Com uma história de lutas e conquistas no ensino fundamental, médio e superior também, a bandeira de luta hoje do MST é a educação infantil. Sem esquecer que quando eles, da organização do movimento, estão falando em educação, o processo de aprendizagem está para além do saber ler e escrever. O objetivo é uma formação integral, que inicia no ensino infantil e "termina" no ensino superior, porque na verdade jamais termina, pois à medida que vão sendo formados passam a ser formadores no movimento.

O MST também enfrenta problemas em relação ao ensino médio, promovido pela SEDUC de forma modular, pois os professores vêm sem nenhuma formação para compreender a realidade na qual estão se inserindo. O número de alunos é alto, varia entre 6.000 e 605.000 em todas as áreas em que atuam, público que precisa ser olhado de maneira diferenciada, posto que assim se constitui.

O MST conta com número que varia entre 220 e 230 "educadores" em todas as áreas, sem referir os do ensino médio enviados pela SEDUC, conforme relatado anteriormente, e os do ensino superior, cujo processo de participação é outro. Vale atentar que a Sra. Maria Raimunda fala de educadores e não de professores, compreensível se lembrarmos que está falando em formação integral e não apenas de escolarização formal como a que acontece nas áreas urbanas.

Entre ensino médio e superior (envolvendo os cursos de graduação, especialização e mestrado) são 78 alunos do convênio com o PRONERA no Pará, cursando: Agronomia, Letras, Técnico em Saúde Comunitária, 
Agropecuária, História, Artes, Direito, Técnico em Administração de Cooperativas, de acordo com o balanço de 2008.

Os convênios em geral são feitos apenas com universidades e escolas públicas por orientação do próprio MST. Mas no último ano ganharam algumas bolsas para o Curso de Gestão, na Universidade Metodista de Minas Gerais, onde cerca de 50 alunos são do MST.

A proposta do movimento agora é, de acordo com a Sra. Maria Raimunda, a de fazer a experiência do ensino integral, com atividades diversas como música, dança, criação de pequenos animais e agricultura, afora as atividades contidas no processo educacional convencional. Outra possibilidade apontada por ela é a de os alunos irem alguns dias da semana para a escola, mas ficarem o dia todo, como: segunda, terça e quarta, ensino de $5^{\mathrm{a}}$ a $8^{\mathrm{a}}$, o dia inteiro; quinta, sexta e sábado, ensino de $1^{\text {a }}$ a $4^{\text {a }}$; e no meio trabalhar a educação infantil. Propostas pensadas com o intuito de facilitar a vida e o processo de educação escolar/formação das crianças de forma geral e de suas famílias também, conforme sua fala.

Hoje, o diário de campo na escola ${ }^{13}$, uma atividade que começou em regime de experiência, tem tido resultados positivos, posto que incentiva as crianças a escrever sobre o seu dia, estimulando a escola a posteriormente realizar a leitura do escrito, o que tem permitido às crianças, além do treinamento da escrita e leitura, a reflexão sobre as atividades e o meio na qual estão inseridas.

A luta dos movimentos sociais do campo e dos movimentos indígenas tem resultado em conquistas significativas para a garantia de educação escolar diferenciada, sobretudo no ensino superior, com oferta de cursos por diferentes instituições de ensino. A partir do campus da UFPA em Marabá, por exemplo, foram e estão sendo ofertados cursos aos movimentos sociais do campo, tais como os de Agronomia, Pedagogia e

\footnotetext{
${ }^{13}$ Esta experiência foi usada anteriormente pelo MST num curso de Agronomia ofertado para assentados de reforma agrária na UFPA, no ano de 2004. Os estudantes tinham um caderno dado pelo MST onde registravam diariamente suas impressões acerca do curso: professores; disciplinas; metodologias de ensino; relação com os demais estudantes na universidade, entre outros aspectos. Havia uma equipe, entre estudantes e dirigentes do MST, responsável por ler esses diários e levantar questões nas reuniões de planejamento do curso com os professores que o coordenavam na universidade, equipe da qual eu fazia parte. O material foi de grande importância para identificar problemas relativos sobretudo à metodologia de trabalho dos professores que atuaram no curso. Pela fala de Maria Raimunda, vemos que a experiência apresentou bons resultados, uma vez que está sendo usada para outros contextos de educação formal no movimento.
} 
Educação do Campo; o Instituto Federal de Educação, Ciência e Tecnologia do Pará (IFPA), a partir do seu Campus Rural de Marabá (CRM) oferece cursos técnicos e de graduação para povos indígenas e para agricultores, entre eles estão: Agricultura Camponesa com ênfase em Agroecologia; Técnico em Agroecologia; Técnico em Agropecuária; Licenciatura Plena em Educação do Campo - PROCAMPO ${ }^{14}$.

\section{Palavras finais...}

Como se vê, a diversidade sociocultural é uma forte marca no espaço social do Território Sudeste Paraense; os diferentes agentes sociais que tomam posições relativas nos diferentes campos de luta, poder e forças em interação no Território possuem objetos de disputas comuns, parafraseando Bourdieu (1989), mas que se diferenciam de acordo com a visão que cada grupo possui do que seja o território para si.

Essas construções nem sempre são consideradas por parte do poder público e/ou privado que atuam na região, e requerem também dos movimentos e associações ajustes nas negociações seja com o poder público, seja com os seus pares, seja com o capital privado. Os territórios concebidos pelos agricultores familiares devem ter terras agricultáveis, com condições de escoamento da produção, com condições adequadas de moradia, com oferta de educação escolar diferenciada e de qualidade para os agricultores e seus filhos, com escolas que funcionem em prédios próprios, com condições de reprodução de seus saberes e técnicas, entre outros fatores.

Cada povo indígena que está no Território Sudeste Paraense tem sua própria representação de território que engloba aspectos materiais e imateriais da cultura de cada povo: terra; cosmologia; mitologia; cultura material; reprodução sociocultural.

A educação escolar para os movimentos indígenas e sociais do campo faz parte do processo de territorialização por eles construído; quando realizada de forma específica para cada realidade dos agentes

14 O Programa de Apoio à Formação Superior em Licenciatura em Educação do Campo (PROCAMPO) é um programa do governo federal criado em 2009 que fomenta a implementação de cursos superiores em licenciatura em educação do campo nas instituições públicas de ensino, tendo como público-alvo os educadores que queiram atuar nas escolas rurais, nos anos finais do ensino fundamental e do ensino médio. 
sociais em interação no campo da educação no espaço social Território Sudeste Paraense, é instrumento para o fortalecimento da identidade de cada grupo socialmente diferenciado, evidenciando que não há como promover o desenvolvimento rural sustentável no Brasil, que é o objetivo do Programa Territórios da Cidadania, sem que se considere a dimensão do etno no desenvolvimento.

As estratégias adotadas por movimentos sociais indígenas e do campo quanto à educação escolar revelam, do meu ponto de vista, que não há como o Estado garantir o direito à diferença sem o protagonismo desses agentes sociais, sem a prática do etnodesenvolvimento e 0 respeito à diversidade.

\section{Referências bibliográficas}

ALMEIDA, Alfredo Wagner Berno de. Terras de preto, terras de santo, terras de índio: uso comum e conflito. In: Terra de quilombo, terras indígenas, "babaçuais livre", "castanhais do povo", faixinais e fundos de pastos: terras tradicionalmente ocupadas. Manaus. PGSCA-UFAM, Manaus, AM, 2008. p. 133-178.

ASSIS, William Santos de. A construção da representação dos trabalhadores rurais no Sudeste Paraense. 2007. 242 f. Tese (Doutorado em Desenvolvimento, Agricultura e Sociedade) - UFRRJ, Rio de Janeiro, RJ, [2007].

BELTRÃO, Jane Felipe. Laudo Antropológico: Área Indígena Sororó a propósito da BR-153. Campinas: São Paulo, 1998.

. Povos indígenas e políticas afirmativas ou Antropologia em campo minado.

Tellus, Campo Grande, v. 7, n. 13, p. 27-36, 2007.

BELTRÃO, Jane Felipe; FERNANDES, Rosani de Fatima. Kuputi (berarubu): patrimônio alimentar da cozinha Kyikatêjê. In: BELTRÃO, Jane; MASTOP-LIMA, Luiza (Org.). Diversidade, educação e direitos: etnologia indígena. Belém: IEMCI, 2010. p. 100-110.

BELTRÃO, Jane Felipe; MASTOP-LIMA, Luiza de Nazaré. (Org.). Matemáticas: No Plural! Saberes matemáticos indígenas e sistemas de aferição. Belém: IEMCI/UFPA, 2009.

IEMCI/UFPA, 2010. 
BOURDIEU, Pierre. Questões de sociologia. Rio de Janeiro: Marco Zero, 1983.

. O poder simbólico. Rio de Janeiro/Lisboa: Bertrand Brasil/Difel, 1989.

CONFERÊNCIA NACIONAL POR UMA EDUCAÇÃO DO CAMPO, 2., 2004, Luiziânia, Goiás. Declaração Final por uma Política Pública de Educação do Campo. Luiziânia, Goiás, 2004.

DE REYNAL, Vincent et al. Agriculturas familiares e desenvolvimento em Frente Pioneira Amazônica. Pointe-à-Pitre: Univ. Antilles Guyane, LASAT/CAT UFPA/GRET/DAT/UAG, 1996.

DIAS, Moysés Jefferson Ferreira. Cultivando conhecimentos para colher sustentabilidade: experiência de formação da Escola Família Agrícola de Marabá para a busca de alternativas produtivas para a região. Belém: Universidade Federal do Pará, 2007.

EMMI, Marília. A Oligarquia do Tocantins e o domínio dos castanhais. Belém: UFPA/NAEA, 1999.

FEARNSIDE, Philip Martin. Desmatamento na Amazônia: dinâmica, impactos e controle. Acta Amazonica, Manaus, v. 36, n. 3, p. 395-400, 2006.

FERNANDES, Rosani de Fátima. Educação Escolar Kyikatêjêe: novos caminhos para aprender e ensinar. 2010. 212 f. Dissertação (Mestrado em Direito) - PPGD, UFPA, Belém, PA, [2010].

GODOI, Emília Pietrafesa de. O sistema do lugar: história, território e memória no sertão. In: NIEMEAYER, Ana Maria; GODOI, Emília Pietrafesa de (Org.). Além dos territórios: para um diálogo entre a etnologia indígena, os estudos rurais e os estudos urbanos. Campinas: Mercado de Letras, 1998. p. 97-131.

GUERRA, Gutemberg Armando Diniz. O posseiro da fronteira: campesinato e sindicalismo no sudeste paraense. Belém: UFPA/NAEA, 2001.

HÉBETTE, Jean. Cruzando a fronteira: 30 anos de estudo do campesinato na Amazônia. Belém: EDUFPA, 2004.

LABORATÓRIO SÓCIO-AGRONÔMICO DO TOCANTINS; SECRETARIA DE DEVENVOLVIMENTO TERRITOTIAL. Diagnóstico Socioeconômico e Ambiental da Produção Familiar do Sudeste do Pará e Plano Territorial de Desenvolvimento Rural Sustentável. Marabá, Pará, 2006.

Plano Territorial de Desenvolvimento Rural Sustentável do Sudeste Paraense. Marabá, Pará, 2010. 
LARAIA, Roque de Barros; DAMATTA, Roberto. Índios e castanheiros: a empresa extrativa e os índios do médio Tocantins. São Paulo: Difel, 1967.

LUCIANO, Gersem dos Santos. O índio brasileiro: o que você precisa saber sobre os povos indígenas no Brasil de hoje. Brasília: Ministério da Educação, Secretaria de Educação Continuada, Alfabetização e Diversidade; Rio de Janeiro: LACED/Museu Nacional, 2006.

Povos indígenas e etnodesenvolvimento no Alto Rio Negro. In: ATHIAS, Renato; PINTO, Regina Pahim (Org.). Estudos indígenas: comparações, interpretações e políticas. São Paulo: Contexto, 2008. p. 27-44.

MASTOP-LIMA, Luiza de Nazaré. O tempo antigo entre os Suruí/Aikewára: um estudo sobre mito e identidade étnica. 2002. 212 f. Dissertação (Mestrado em Antropologia) - Mestrado em Antropologia, UFPA, Belém, PA, [2002].

MASTOP-LIMA, Luiza de Nazaré; BELTRÃO, Jane Felipe. Identidade e território: saga, construção e situação de etnicidade entre agricultores familiares (PA Belo Horizonte Pará - Brasil). Tessituras, Pelotas, v. 3, n. 1, p. 64-97, jan/jun 2015.

MATTA DA SILVA, Gilmar. Sapurahái de Karuára: mitos, instrumentos musicais e canto entre os Suruí Aikewára. 2007. 170 f. Dissertação (Mestrado em Antropologia) PPGCS, UFPA, Belém, PA, [2007].

NAVEGANTES-ALVES, Lívia. Pratiques de gestion du pâturage et envahissement par les adventices chez les éleveurs bovins en Amazonie Orientale. 2011. 190 f. Tese (Doutorado em Systèmes Intégrés en Biologie, Agronomie, Géoscience, Hydrologie et Environnement) - École Doctorale SIBAGHE, SupAgro, Montpellier, França, [2011].

OLIVEIRA, Myriam Cyntia Cesar de et al. Consolidação da Agricultura Familiar na Fronteira Agrícola: relatório de atividades. Marabá: UFPA, 2003.

OLIVEIRA FILHO, João Pacheco de (Org.). A Viagem da Volta: etnicidade, política e reelaboração cultural no Nordeste Indígena. Rio de Janeiro: Contra Livraria/LACED, 1999.

PBP. O que é o programa de bolsa permanência. 2014. Disponível em: http://permanencia.mec.gov.br/. Acesso em: 20 set. 2014.

PORTAL DA CIDADANIA. Territórios da cidadania. 2014. Disponível em: http://www.territoriosdacidadania.gov.br/dotlrn/clubs/territriosrurais/xowiki/oprograma. Acesso em: 22 out. 2014.

SAQUET, Marcos Aurélio. Abordagens e concepções sobre território. São Paulo: Expressão Popular, 2007. 
SEEGER, Anthony; VIVEIROS DE CASTRO, Eduardo Batalha. Terras e territórios indígenas no Brasil. Encontros com a Civilização Brasileira, Rio de Janeiro, v. 12, n. 1-2, p. 101-114, 1979.

SEMAS. Secretaria de Meio Ambiente e Sustentabilidade. 2014. Disponível em: www.sema.pa.gov. Acesso em: 18 set. 2014.

SILVA, Gilmar Matta da; BELTRÃO, Jane Felipe; MASTOP-LIMA, Luiza de Nazaré. Mitos e histórias Aikewára: conhecendo a tradição das narrativas orais. Belém: Curso de Produção de Material Didático para a Diversidade/PPGA, 2011. 1 CD-ROM.

SIMÕES, Aquiles. La réforme agraire en Amazonie brésilienne: innovation et apprentissage social. 2006. 444 f. Tese (Doutorado em Espace, Sociétés Rurales et Logiques Économiques) - École Doctorale Temps, Espaces, Sociétés, Cultures, Université de Toulouse II - Le Mirail, Toulouse, [2006].

VELHO, Otávio Guilherme. Frentes de expansão e estrutura agrária: estudo do processo de penetração numa área da Transamazônica. Rio de Janeiro: Zahar Editores, 1972.

Recebido em: 26/05/2015* Aprovado em: 24/09/2015* Publicado em: 31/12/2015 